\title{
Development of the material property handbook and database of $\mathrm{CuCrZr}$
}

${ }^{1}$ Karlsruhe Institute of Technology, Institute for Applied Materials, Hermann-von-Helmholtz-Platz 1, 76344 Eggenstein-Leopoldshafen, Germany

${ }^{2}$ Max Planck Institute of Plasma Physics, Boltzmannstraße 2, 85748 Garching, Germany

3UK Atomic Energy Authority, Culham Science Center, Abingdon, Oxfordshire, OX14 3DB, UK

Kuo Zhang ${ }^{1,2}$, Ermile Gaganidze ${ }^{1}$, Michael Gorley ${ }^{3}$

\begin{abstract}
This paper covers the initial progress on the development of material property handbook (MPH) of baseline CuCrZr, within the Materials Engineering Data and Design Integration (MAT-EDDI) of EUROfusion Material Database and Handbook group. Initial drafting of the baseline CuCrZr MPH structure is presented, with inclusion of available data, figures and general information. A data reviewing procedure is discussed for qualification of the data of $\mathrm{CuCrZr}$ by comparing raw data from a large variety of resources. If the data scattering is acceptable, average and minimum curves are fitted as suggestions for the European DEMO (EU-DEMO) design. Specific missing properties as well as gaps in the database for EU-DEMO are identified.
\end{abstract}

\section{Key words}

CuCrZr; Material Property Handbook; EU-DEMO

Abbreviation
\begin{tabular}{|l|l|}
\hline AT & Arbeitskreis Thermophysik \\
\hline CTE & Coefficient of Thermal Elongation \\
\hline DSC & Differential Scanning Calorimetry \\
\hline ER & Electric Resistivity \\
\hline EU-DEMO & European DEMO \\
\hline HT & Heat Treatment \\
\hline IG & ITER Grade \\
\hline LCF & Low Cycle Fatigue \\
\hline LFA & Laser-Flash Apparatus \\
\hline MPH & Material Property Handbook \\
\hline PA & \#Heat treatment defined in section 1.2 \\
\hline RT & Room Temperature \\
\hline SA & Solution Annealing \\
\hline
\end{tabular}




\begin{tabular}{|l|l|}
\hline SAA & \#Heat treatment defined in section 1.2 \\
\hline SAcwA & \#Heat treatment defined in section 1.2 \\
\hline SAoverA & \#Heat treatment defined in section 1.2 \\
\hline SCA & \#Heat treatment defined in section 1.2 \\
\hline SD & Standard Deviation \\
\hline SDC-IC & Structural Design Criteria for In-Vessel Components \\
\hline TC & Thermal Conductivity \\
\hline UIUC & University of Illinois at Urbana-Champaign, Urbana \\
\hline UTS & Ultimate Tensile Strength \\
\hline YS & Yield Strength \\
\hline
\end{tabular}

\section{Introduction}

CuCrZr is a precipitation hardening copper alloy. It is characterized by comparatively high strength even at elevated temperatures, high wear resistance and high tempering resistance compared to most copper-based alloys [1, 2]. Currently, $\mathrm{CuCrZr}$ is the prime candidate heat sink material for high heat flux and plasma-facing components in the EU-DEMO divertor [3]. The lower service temperature limit under irradiation lies between $150^{\circ} \mathrm{C}$ and $250^{\circ} \mathrm{C}$ [3]. The recommended upper temperature limit is $350^{\circ} \mathrm{C}$ for long term operation [4]. The mechanical properties and thermal conductivity of this alloy are some of the key properties of interest in component design for fusion power plant [1].

The purpose of the material property handbook (MPH) on $\mathrm{CuCrZr}$ is to provide ready reference and guidance to select the required material properties with engineering trend curves under requirements for design, allowing straightforward use in codes and standards, e.g. Structural Design Criteria (SDC-IC) [5].

To initiate the development of the material database on CuCrZr used for the MPH, literature data has been reviewed and screened. The selected literature was limited for the application in fusion. This paper provides an overview of the literature that has been screened and presents the initial work on the development of the MPH from reviewed literature data.

\section{General information}

\subsection{Chemical composition}

The percentage of chemical compositions in the CuCrZr alloy is designated to satisfy the required mechanical and electrical properties. 
The content of $\mathrm{Cr}$ should be high enough above the solubility limit for the alloy at the solution annealing (SA) temperature to account for $\mathrm{Cr}$ inhomogeneity and low enough to prevent coarse $\mathrm{Cr}$ precipitates which may cause embrittlement of the alloy. $\mathrm{Zr}$ is required for improved homogeneity of precipitates, improved ductility and fatigue resistance. $\mathrm{Zr}$ also increases the solubility of $\mathrm{Cr}$ in the $\mathrm{Cu}-\mathrm{Cr}-\mathrm{Zr}$ system. P content should be kept as low as possible to minimise coarse precipitates which are stable at $\mathrm{SA}$ temperatures of $1050^{\circ} \mathrm{C}[6,7]$.

There are various standards defining the chemical composition ranges for the CuCrZr alloy, for instance EN12163 [8] and C18150 [9]. In the ITER Grade CuCrZr (CuCrZr-IG), the weight percentages (wt\%) have been specified as $\mathrm{Cr}: 0.6 \sim 0.9 \mathrm{wt} \%, \mathrm{Zr}: 0.07 \sim 0.15 \mathrm{wt} \%$ [2]. The other minor alloying elements $(\mathrm{Fe}, \mathrm{Si}, \mathrm{Co}, \mathrm{Cd}, \mathrm{O})$ are rarely mentioned in the literature about $\mathrm{CuCrZr-IG}$.

In the MPH of CuCrZr, a table of chemical compositions has been presented, including the specification in various standards and measured values in different reports or product sheets [8-14]. For the purposes of this paper, only materials meeting the requirements of the ITER grade CuCrZr composition are considered.

\subsection{Heat treatment}

The properties of $\mathrm{CuCrZr}$ alloys are known to be sensitive to heat treatment. Various mechanical properties and also physical properties e.g. electrical/thermal conductivity can be modified with different temperatures and the length of solution annealing and aging times. The cooling rate is also a factor to influence the material properties. For instance, in [11], the yield- and tensile strengths, and also microstructures of specimens with different cooling rates and different aging periods are compared and the highest strength is reported at an aging temperature of $440^{\circ} \mathrm{C}$ irrespective of the cooling rate. For the same aging temperature, the strength is increased with the cooling rate but the difference in the strength became smaller when the CuCrZr alloys were aged over $580^{\circ} \mathrm{C}$.

For the application in ITER or EU-DEMO in the future, several heat treatments are specified for CuCrZr, which are listed as a), b), c), d), e) in the following. The most reported heat treatment in literature is SAA, standing for Solution Annealing and Aging. SAcwA includes cold working before aging. SCA includes HIP-treatments. SAoverA means over-aged. And PA stands for Prime Aging.

a) SAA---- Solution annealing at $980^{\sim} 1000^{\circ} \mathrm{C}$ for $30^{\sim 60} \mathrm{~min}$, water quench and age at $460 \sim 500^{\circ} \mathrm{C}$ for $2 \sim 4$ h. $[2,15,16]$

b) SAcwA--- Solution annealing at $980^{\sim} 1000^{\circ} \mathrm{C}$ for $30^{\sim} 60 \mathrm{~min}$, subsequent cooling in water, further cold working by $40 \sim 70 \%$, and ageing at $450 \sim 470^{\circ} \mathrm{C}$ for $2 \sim 4 \mathrm{~h}$. [16]

c) SCA----received as SAA, HIP-treated at $1040^{\circ} \mathrm{C}$ for $2 \mathrm{~h}$ at $140 \mathrm{MPa}$ followed by solution annealing at $980^{\circ} \mathrm{C}$ for $0.5 \mathrm{~h}$ with a slow cooling rate of $50^{\sim} 80^{\circ} \mathrm{C} / \mathrm{min}$ between 980 and $500{ }^{\circ} \mathrm{C}$, and final aging at $560^{\circ} \mathrm{C}$ for $2 \mathrm{~h}$. [15] 
d) SAoverA----Solution annealing and ageing at non-optimal condition (over-aged) due to specific manufacturing processes. [16]

e) PA----Reported in a series of papers of B.N. Singh et al. [17-19], material supplied by Outokumpu Oyj (Finland) [20]: solution annealed at $960^{\circ} \mathrm{C}$ for $3 \mathrm{~h}$, water quenched and then prime aged (PA) at $460^{\circ} \mathrm{C}$ for $3 \mathrm{~h}$.

Although SAA and SAcwA are the two most reported heat treatments, they have never been designated to be the standard heat treatment for $\mathrm{CuCrZr}$, since researches still continue to study the influence of heat treatment/ cold working on the mechanical properties of this alloy, by e.g. modifying the solution annealing temperature or period, cold working degree, aging temperature or period, or by further treatment such as HIP-treatments.

\subsection{Content in the MPH of CuCrZr}

The material properties have been grouped to mechanical properties and thermo-physical properties in the MPH as follows.

A: Mechanical properties:
A1. Young's modulus

A2. Stress-strain curve

A3. Yield strength

A4. Ultimate tensile strength

A5. Uniform elongation

A6. Total elongation

A7. Hardness

A8. Fatigue

A9. Creep-fatigue

a) Stress-controlled tests

b) Strain-controlled tests

c) Balanced load, extension-controlled

A10. Creep

A11. Fracture toughness

A12. Charpy impact strength

B: Thermo-physical properties:

B1. Coefficient of thermal expansion

B2. Density

B3. Specific heat

B4. Thermal conductivity

B5. Electric resistivity

These properties have been selected for the need to derive the required design curves to match 
the design requirements, which can explain the performance of the material covering the anticipated failure modes. It also matches with existing properties collected for Eurofer97 [21, 22].

Due to the variety of $\mathrm{CuCrZr}$ alloys in terms of chemical compositions and heat treatments, even within the ITER Grade, the mechanical and physical properties will differ one from the other. The measured values in various laboratories will be also different from each other due to, for instance, various specimen sizes, accuracy of measurement equipment, loading type and rate, environments (air or vacuum), and so on.

The new MPH of CuCrZr includes all available information and tries to reveal the sensitivity of the material properties to each influencing factor. If the chemical compositions in the reviewed literature are not within the ITER-IG specification, or the temperature and period of solution annealing and aging are not within the five specifications (SAA, SAcwA, SAoverA, SCA, PA) mentioned above,they will be then specially pointed out in the diagrams or text in the MPH.

If the mechanical / physical properties agree well with each other, average curves have been proposed for the CuCrZr alloys to show the relationship between material properties and the testing temperatures. Minimum curves have been also proposed with a distance of 1.96 times the standard deviation (SD), according to ITER Structural Design Criteria for In-Vessel Components (SDC-IC) [5].

To ensure acceptability, the selected literature data have been reassessed aiming at completion of the required information or at judgement of the validity of the collected results according to the international testing standards, e.g. ASTM standards.

Due to a large amount of information in the MPH of CuCrZr, the following part of the current paper will present selectively some important diagrams with discussions from the MPH.

\section{Tensile properties}

The section on tensile properties includes Young's modulus, stress-strain curves, yield strength (YS) and ultimate tensile strength (UTS), uniform and total elongation.

It is supposed that the reliable data for Young's modulus will be issued from sonic measurements, namely dynamic method. However, until now there is no available report claiming the Young's modulus was measured with this dynamic method. Hence it is supposed that all available Young's modulus of $\mathrm{CuCrZr}$ are determined from the tensile stress-strain curves, although it is not everywhere mentioned. Fig. 1 collects the Young's modulus of SAA and SAcwA specimens from several reports. The average and minimum curves are fitted for both SAA and SAcwA specimens. 


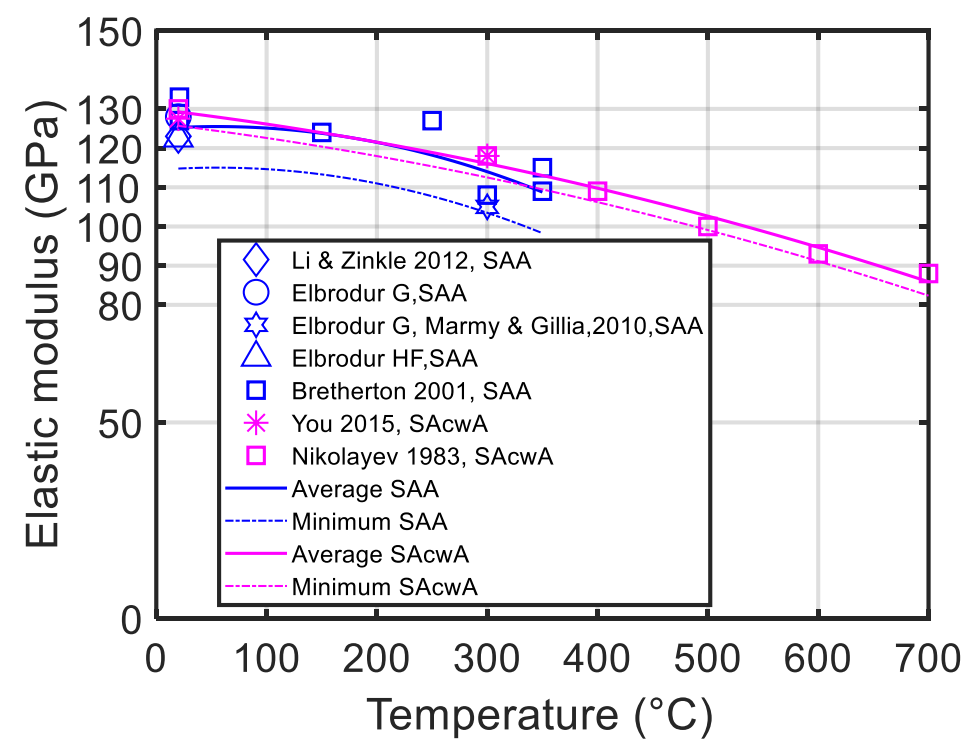

Fig. 1 Young's modulus versus temperatures. [1, 7, 23-25]

The equations for fitting curves of Young's modulus are as follows:

$\mathbf{E}_{\text {average, } \mathrm{SAA}}(\mathrm{T})-\mathrm{GPa}=-1.9234 \times 10^{-4} \times T^{2}-2.1233 \times 10^{-2} \times T+124.91 \quad\left(\mathrm{SD}=5.35, \mathrm{~T}-{ }^{\circ} \mathrm{C}\right) \quad$ eq. 1

$\mathbf{E}_{\text {average,SAcwA }}(\mathrm{T})-\mathrm{GPa}=-4.1707 \times 10^{-5} \times T^{2}-3.3692 \times 10^{-2} \times T+129.91\left(\mathrm{SD}=1.81, \mathrm{~T}-{ }^{\circ} \mathrm{C}\right) \quad$ eq. 2

In order to build analytical or numerical material model, it is more proper to use data from true stress-strain curves. Normally a dog-bone shaped flat sample should be used together with video record, with which the true stress-strain curve can be calculated. However, such reported result is not yet available today. Hence all the stress-strain curves collected in the MPH of $\mathrm{CuCrZr}$ are engineering stress-strain curves.

The stress-strain curves are available at several testing temperatures like room temperature, $150^{\circ} \mathrm{C}, 200^{\circ} \mathrm{C}, 250^{\circ} \mathrm{C}, 300^{\circ} \mathrm{C}, 400^{\circ} \mathrm{C}, 500^{\circ} \mathrm{C}$ and $600^{\circ} \mathrm{C}$.

The $0.2 \%$-yield strength (YS) and ultimate tensile strength (UTS) in the temperature range $20-700^{\circ} \mathrm{C}$ are collected from various reports, as illustrated in Fig. 2 . The fitted average curves of yield strengths vs. testing temperatures are quadratic, while linear relationships are revealed between the UTS and the testing temperatures, for both groups of specimens with or without cold working. 


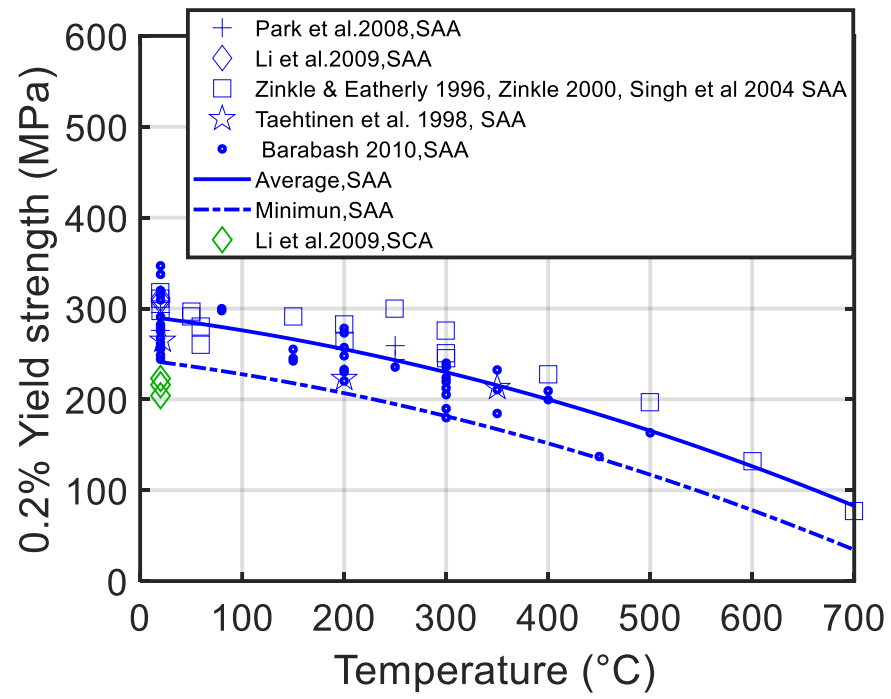

a) $0.2 \%$-Yield strengths of SAA and SCA specimens $[2,11,15,16,26-29]$

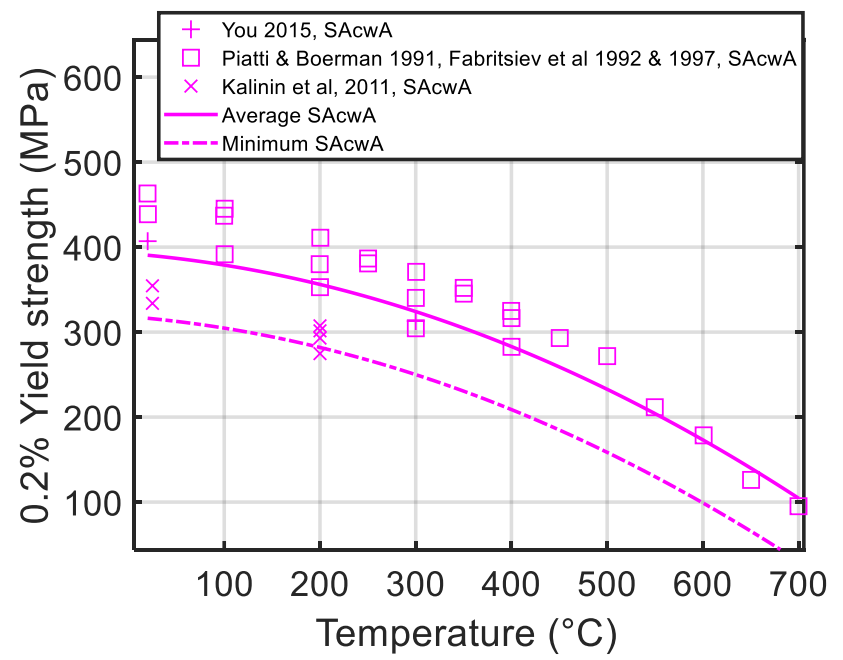

b) $0.2 \%$-Yield strengths of SAcwA specimens $[1,2,16,30]$ 


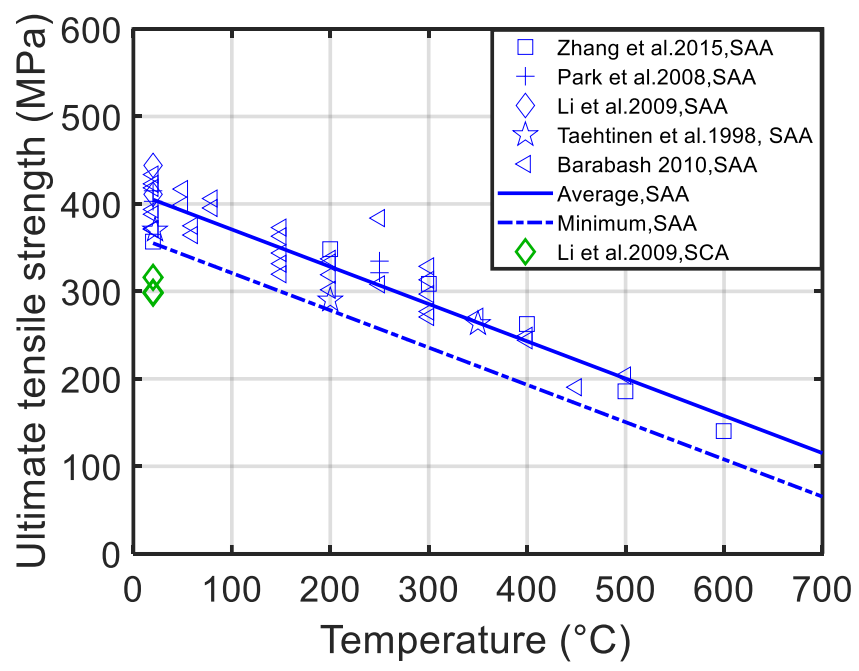

c) Ultimate tensile strengths of SAA and SCA specimens $[11,12,15,16,26]$

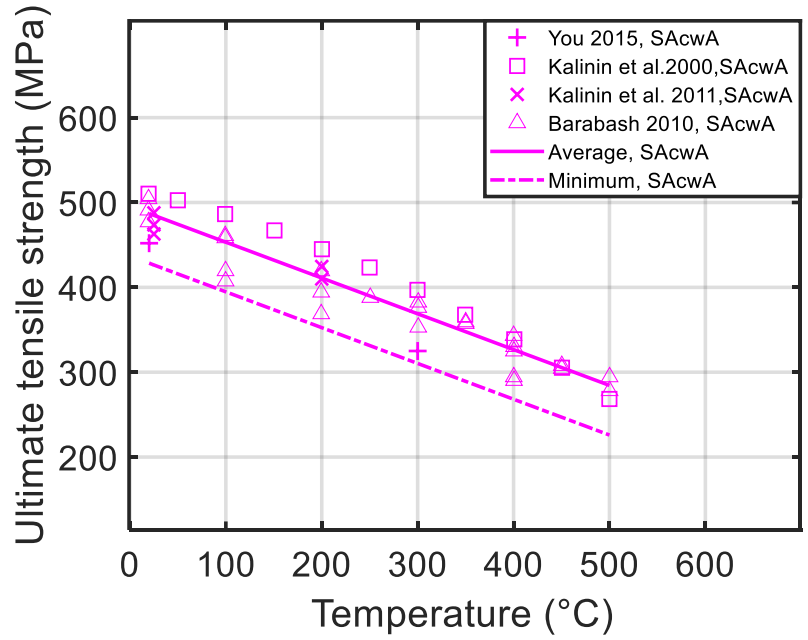

d) Ultimate tensile strengths of SAcwA specimens [1, 16, 30, 31]

Fig. 2 Yield and ultimate tensile strengths versus temperatures.

The equations for the fitting curves/lines of YS and UTS are as follows:
YS $_{\text {average, SAA }}(\mathrm{T})-\mathrm{MPa}=-2.2847 \times 10^{-4} \times T^{2}-0.13931 \times T+292.19$
$\left(\mathrm{SD}=24.663, \mathrm{~T}-{ }^{\circ} \mathrm{C}\right)$
eq. 3
$\mathbf{Y S}_{\text {average, SAcwA }}(\mathrm{T})-\mathrm{MPa}=-4.5936 \times 10^{-4} \times T^{2}-0.089841 \times T+392.46 \quad\left(\mathrm{SD}=37.84, \mathrm{~T}^{\circ} \mathrm{C}\right) \quad$ eq. 4
UTS $_{\text {average, SAA }}(\mathrm{T})-\mathrm{MPa}=-0.42631 \times T+413.45 \quad\left(\mathrm{SD}=25.415, \mathrm{~T}-{ }^{\circ} \mathrm{C}\right)$
eq. 5
$\mathbf{U T S}_{\text {average, SAcwA }}(\mathrm{T})=-0.4219 \times T+495.4 \quad\left(\mathrm{SD}=29.85, \mathrm{~T}^{-}{ }^{\circ} \mathrm{C}\right)$
eq. 6

When comparing the strengths of different groups of specimens, it is found that cold working increases both the yield and ultimate tensile strengths by approximately $100 \mathrm{MPa}$. And 
specimens with HIP-treatments (SCA) have relatively lower yield and ultimate tensile strengths. However the data for SCA specimens are only available at room temperature [15]. More data are required at elevated temperatures to evaluate the effect of HIP-treatments.

The uniform and total elongations are also collected from various reports for the MPH of CuCrZr. The data points are collected in Fig. 3. Comparing to other material properties, the elongation values are relatively rare and scatter too much to propose convincing average curves for the design. In spite of the data scattering, it is obvious that cold working decrease both uniform and total elongation. Note that the HIP-treatments decrease both strength and elongation, while cold working decreases the elongation but increases the strength, as shown in Fig. 2 and Fig. 3.

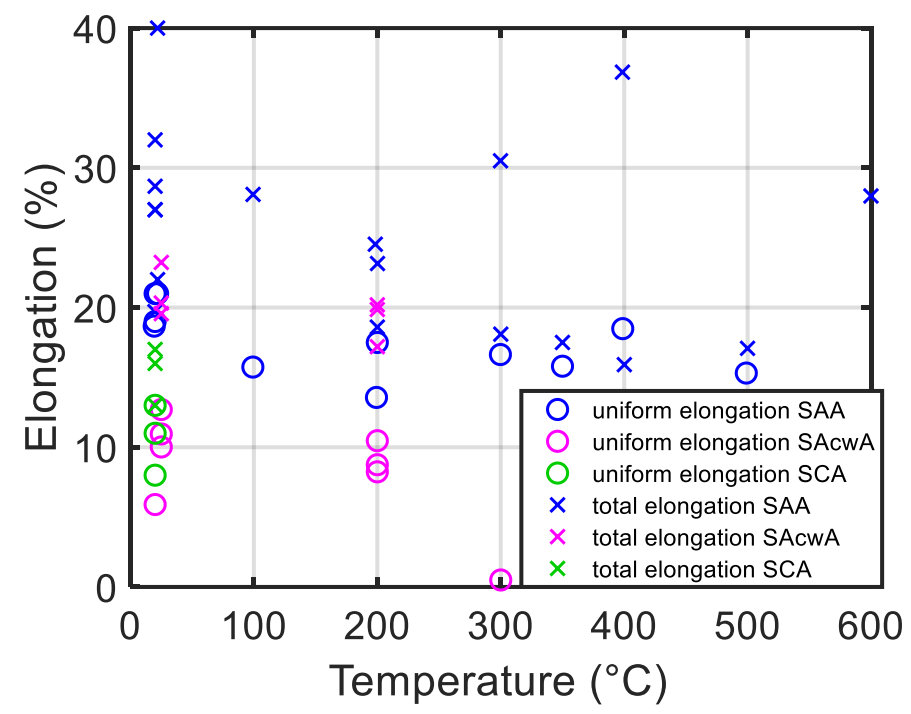

Fig. 3 Uniform and total elongations versus temperatures [1, 15, 26, 30-33]

\section{Fatigue and creep}

Mechanical properties such as fatigue, creep and creep-fatigue behavior are collected for the $\mathrm{MPH}$ of $\mathrm{CuCrZr}$.

To evaluate the influence of testing temperatures on the low cycle fatigue (LCF) behavior, the values which originate from University of Illinois at Urbana-Champaign, Urbana (UIUC) are gathered in Fig. 4. No clear temperature trend is found between data points from room temperature to $350^{\circ} \mathrm{C}$. Although data points for $500^{\circ} \mathrm{C}$ form the lower boundary. Hence, the test temperature $\left(<500^{\circ} \mathrm{C}\right)$ has marginal influence on the lifetime in LCF tests. 


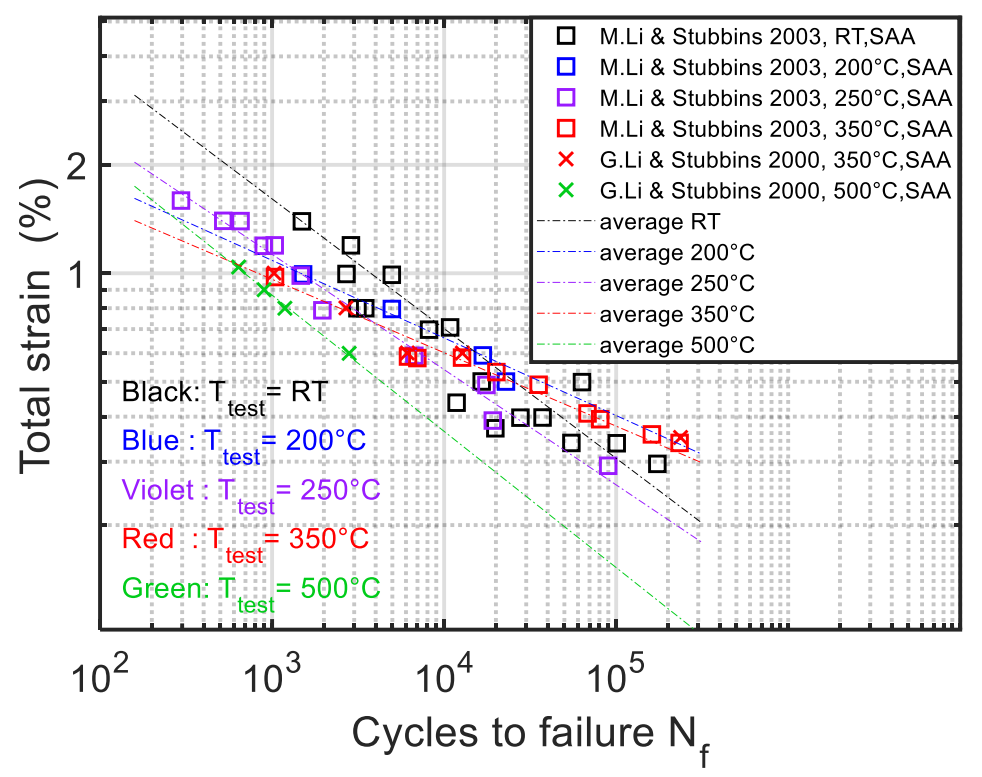

Fig. 4 Total strains versus number of cycles to failure of tests performed in UIUC [34, 35]

The relationships of total strains versus testing temperatures are shown separately for SAA and SAoverA in Fig. 5. Coffin-Manson fittings are performed for the two groups of data points. The over-aging increases the fatigue life of $\mathrm{CuCrZr}$, which is obvious in the report of Marmy [24]. The specimens have been aged at $580^{\circ} \mathrm{C}$ for 2 hours, comparing to $460^{\sim} 500^{\circ} \mathrm{C}$ as the aging temperature for SAA specimens.

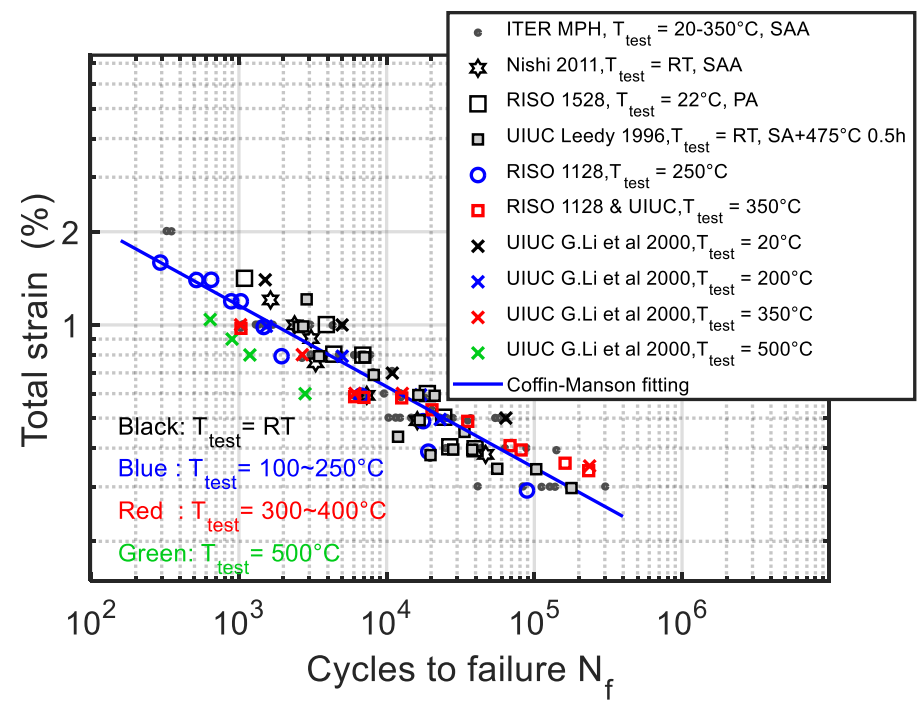

a) 


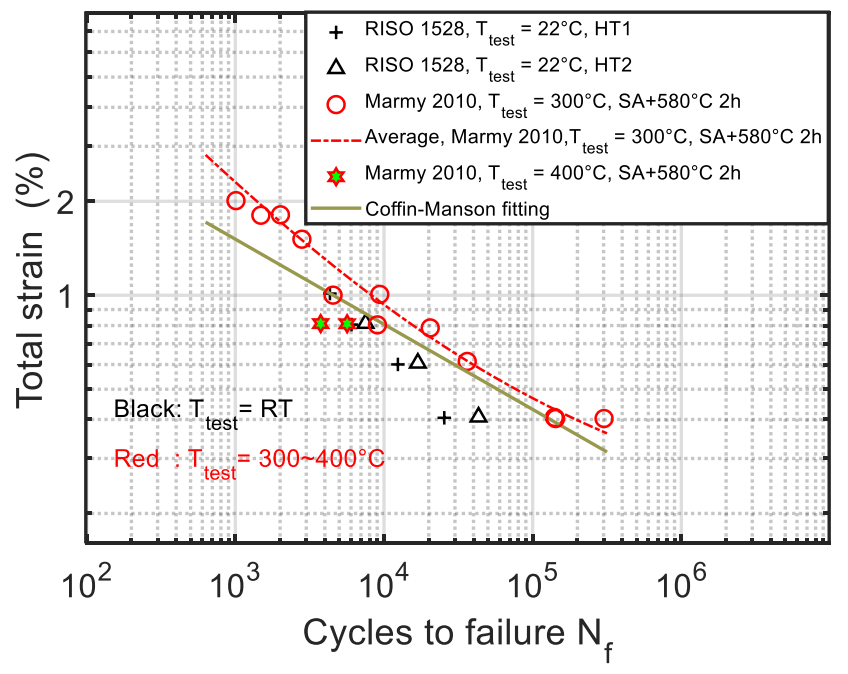

b)

Fig. 5 Total strains versus number of cycles to failure of tests of a) SAA specimens and b) SAoverA specimens $[18,24,34-38]$

The fitted Coffin-Manson equations for SAA and SAoverA specimen are as follows:

$\begin{array}{lll}\frac{\Delta \varepsilon_{S A A}}{2}=3.5286 \times N_{f}^{-0.26199} & (\Delta \varepsilon-\%) & \text { eq. } 7 \\ \frac{\Delta \varepsilon_{\text {SAoverA }}}{2}=4.9741 \times N_{f}^{-0.27269} & (\Delta \varepsilon-\%) & \text { eq. } 8\end{array}$

The proposed Coffin-Manson equation by Marmy [24] for the overaged specimens (aged at $580^{\circ} \mathrm{C}$ for 2 hours and tested at $300^{\circ} \mathrm{C}$ ) is as follows:

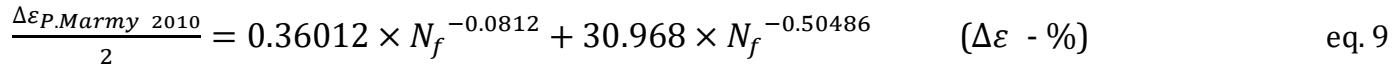

The available data for creep is only found in the two reports of Marmy et al. [24, 39], which have collected even earlier data points. The data points are summarized in Fig. 6. 


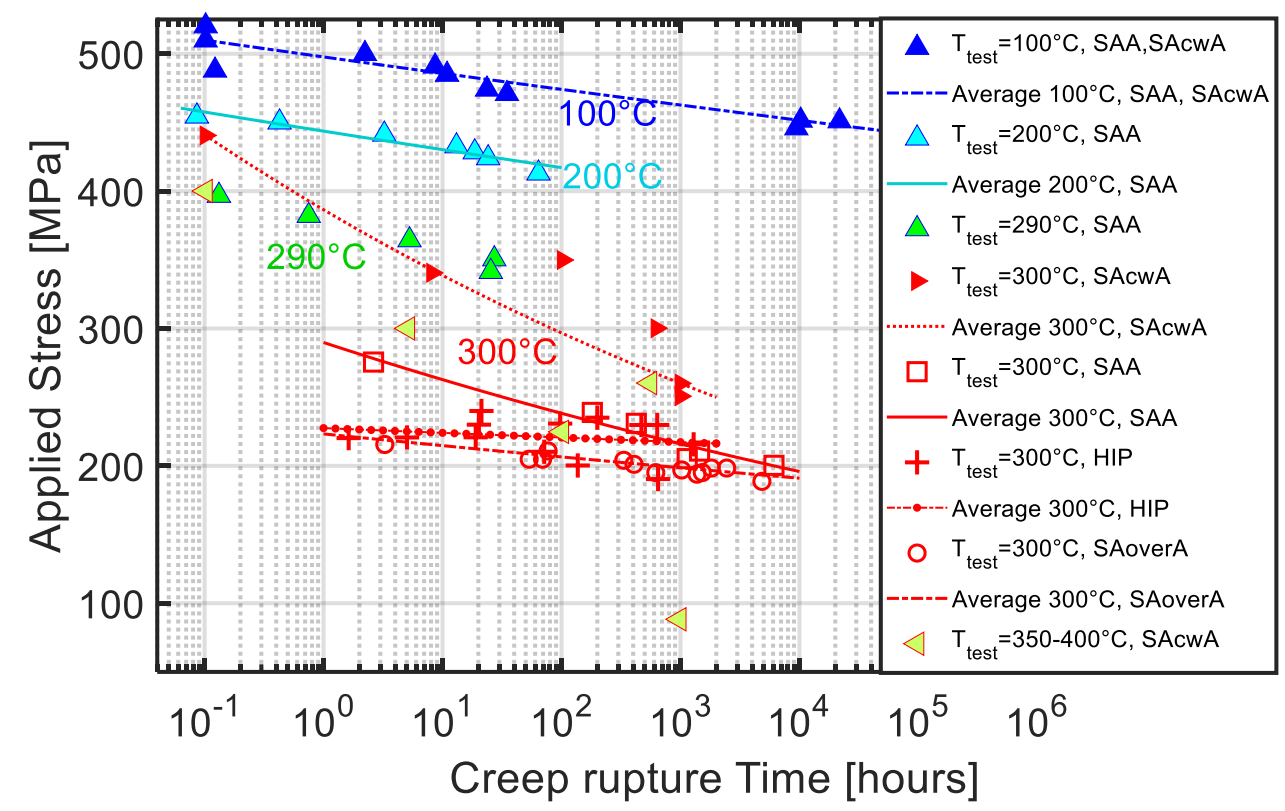

Fig. 6 Creep rupture times versus applied stresses at different testing temperatures. [24, 39]

Data points for $100^{\circ} \mathrm{C}$ match with each other, no matter which heat treatment, cold working or chemical composition there are. Only one group of data exists for $200^{\circ} \mathrm{C}$, which has lower applied stress than those at $100^{\circ} \mathrm{C}$.

The data points for temperatures over $290^{\circ} \mathrm{C}$ scatter in a large range. The data from the cold worked alloy form the upper boundary while those from over-aged alloy form the lower boundary. Data points of SAA specimens and those with HIP-treatments lie in between.

For a convincing suggestion to the design, more creep tests are required.

Singh et al. have performed a thorough investigation of creep-fatigue behavior of $\mathrm{CuCrZr}$ and reported their results in Ris $\emptyset-\mathrm{R}-1528(E N)$ in 2005 [18]. The material was supplied by Outokumpu Oyj [20] with compositions of $\mathrm{Cu}-0.73 \% \mathrm{Cr}-0.14 \% \mathrm{Zr}$, which is within the specified chemical compositions of the ITER Grade CuCrZr. The heat treatments of the specimens include prime aging (PA), which differs itself from traditional SAA by longer solution annealing period ( $3 \mathrm{~h}$ ). There have been also other heat treatments in the work of Singh et al. [18], including HT1, HT2. HT1 means PA specimens are further aged in vacuum at $600^{\circ} \mathrm{C}$ for one hour. HT2 means PA specimens are further aged in vacuum at $600^{\circ} \mathrm{C}$ for four hours.

Singh et al. [18] have performed three groups of creep-fatigue tests: a) stress-controlled, b) strain-controlled, and c) extension-controlled. Since the results have been clearly presented in [18], there is no need to repeat their diagrams in the current paper. Note that Singh et al. [18] have reported ratcheting behavior in the stress-controlled creep-fatigue tests, however without further evaluation. There have been till now no available research on the ratcheting behavior of CuCrZr. 


\section{Thermo-physical properties}

Thermo-physical properties collected for the current MPH of $\mathrm{CuCrZr}$ include coefficient of thermal elongation (CTE), density, specific heat, thermal conductivity and electric resistivity.

Pintsuk et al. [40] have reported a thorough investigation on the thermo-physical properties, namely "Interlaboratory tests", where eight European laboratories and a company Netzsch as an external reference laboratory have took part in, to perform thermo-physical tests on specimens from the same batch of material. The material for this "Interlaboratory tests" was taken from a bar material $\left(35 \times 35 \times 1000 \mathrm{~mm}^{3}\right)$ produced by the company Zollern/Laucherthal [41]. The composition is $\mathrm{Cu}-0.8 \mathrm{Cr}-0.08 \mathrm{Zr}$ (in mass\%) with low hardness when compared to other $\mathrm{CuCrZr}$ grades. Its production process consists of solution annealing at $970{ }^{\circ} \mathrm{C}$ for $20 \mathrm{~min}$ followed by water quenching and aging at $475^{\circ} \mathrm{C}$ for 2 hours. The measured data may scatter from each other due to various unknown experimental conditions.

The measurements of coefficient of thermal elongation have been performed with push-rod dilatometry. The majority of the laboratories provided data within a standard deviation of $\sim 3 \%$ from the average. Only the results of two laboratories are located outside this range representing the lower threshold (TU-Vienna) and the upper threshold (Netzsch) of the measured CTE data by an offset of $\pm 5 \%$ in comparison to the average. Since there is no reason to exclude either result, both data sets were taken into account and due to its symmetric spread around the average, they balance each other.

The value of density has been measured at room temperature and calculated for $\mathrm{T}>\mathrm{RT}$ with data of coefficient of thermal expansion.

The specific heats have been measured both by Differential Scanning Calorimetry (DSC) and by Laser-Flash Apparatus (LFA). The specific heats measured on $5 \mathrm{~mm}$ thick LFA specimens scatter $2 \%$ to $4 \%$ from the average measured by DSC, while the values measured on $3 \mathrm{~mm}$ thick specimen are in very good agreement within the standard deviation of the DSC measurement.

Thermal conductivity (TC) is the most reported thermo-physical property in literature. In the "Interlaboratory tests", the TC has been calculated via the formula

$\lambda(T)=a(T) \rho(T) c_{P}(T)$ eq. 10

where $\lambda$ is thermal conductivity, $a$ is thermal diffusivity, $\rho$ is material density and $c_{p}$ is specific heat.

For the MPH of CuCrZr, data for TC from more sources are collected. In Fig. 7, the data points and curves are shown. 


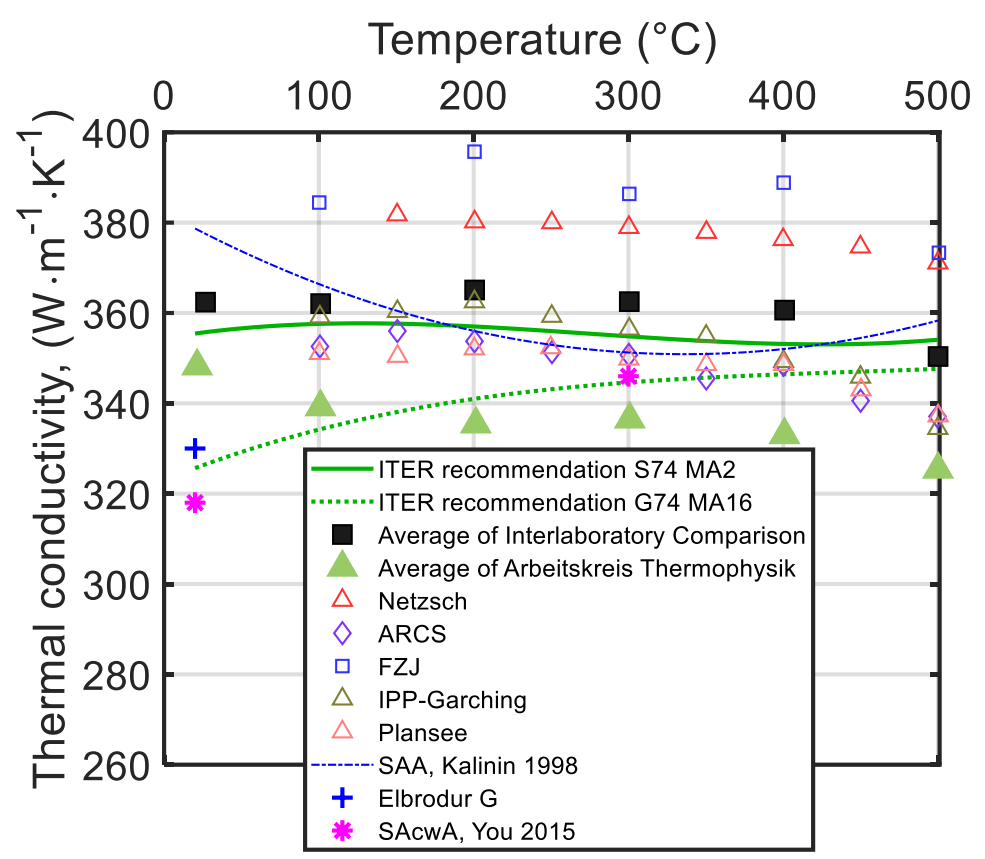

Fig. 7 Thermal conductivities versus temperatures. $[1,14,29,40,42,43]$

Fig. 7 shows average thermal conductivity values as well as values from various laboratories in the "Interlaboratory tests". Data points and curves from other sources are also shown in this diagram. Pintsuk et al. [40] have also reported another investigation campaign "Arbeitskreis Thermophysik" (AK), where the thermal conductivity of the same material have been measured. These values from AK are also shown in Fig. 7.

Further, two ITER documents $[42,43]$ are found for the thermal conductivity. These two ITER documents have referred to different sources and have proposed different average curves for the thermal conductivity versus temperature. The difference decreases with increasing temperature. These two curves are also shown in Fig. 7.

The suggested average TC1 by [43] is closer to the results from "Interlaboratory tests", while the suggested average TC2 by [42] is closer to the results from "Arbeitskreis Thermophysik".

Electric resistivity (ER, $\rho$ ) can be calculated from thermal conductivity $(\lambda)$ according to Wiedemann-Franz relation: $\lambda \cdot \rho=L \cdot T$, where $T$ is the absolute temperature and $L$ is the Lorentz number $2.45 \times 10^{-8} \mathrm{~W} \cdot \mathrm{Q} \cdot \mathrm{K}^{-1}$.

\section{Gaps in the database}

Gaps and non-ideal integration of available data have been discussed respectively for the material properties. Several properties are missing in the database, for instance reduction of area during tensile tests, Poisson's ratio and ratcheting behavior. 
Generally, there remains a significant volume of missing data to provide sufficient material properties to enable the full design of EU-DEMO divertor components using CuCrZr. A crucial point is that, the variations of the metallurgical parameters during production procedure have strong influence on the mechanical properties of this material. The specimens from different semi-finished product forms have to be characterized in order to assess the effect of different fabrication procedures (for instance hot radial pressing) on the material properties.

The closing of the database gaps under specified heat treatments should be complemented, including tests after material has been exposed to long term aging conditions mimicking component operation, as well as after dedicated thermo-mechanical treatments simulating the application relevant joining technologies.

To provide convincing design rules, more mechanical tests are expected. For instances, as mentioned in section 2 while discussing the tensile properties of this material, tests are expected to generate the true stress-strain curves at various testing temperatures, to support building of analytical or numerical material models. Besides, more tests for various damage modes are expected, including ratcheting, exhaustion of ductility, fatigue and creep-fatigue.[44]

Irradiation campaigns has been launched for $\mathrm{CuCrZr}$ upto $5 \mathrm{dpa}$, irradiation temperatures ranging between $100^{\circ} \mathrm{C}$ and $300^{\circ} \mathrm{C}$, for determination of the design relevant mechanical and thermo-physical properties in the irradiated state for base materials and joints. Results including tensile, toughness and LCF properties from post irradiation examination are expected to be available before 2020.[44]

\section{Summary}

The current paper has reported the early development of EUROfusion material database and material property handbook on ITER-Grade CuCrZr. The database currently includes around 1000 raw material data records taken from literature and screened for acceptability. It is found that the material properties are marginally influenced by factors such as chemical composition, specimen size and loading rates, however are very sensitive to factors including heat treatment and cold working. Various periods and temperatures during solution annealing and aging, as well as various cooling rates, lead to very different material properties. When meaningful, the best estimate trend and minimum curves are proposed for ITER-Grade alloys. Definition of the baseline CuCrZr material and relevant heat treatments will be required in the future, in terms of a) Industrial fabrication of large charge of baseline CuCrZr. b) Characterization campaign for generation of consistent mechanical and thermo-physical data.

\section{Acknowledgements}

This Work has been carried out within the framework of the EUROfusion Consortium and has 
received funding from the Euratom research and training programme 2014-2018 and 2019-2020 under grant agreement No 633053. M. Gorley would also like to thank the RCUK Energy Programme under grant EP/1501045. The views and options expressed herein do not necessarily reflect those of the European Commission.

\section{References}

[1] J.-H. You, "Copper matrix composites as heat sink materials for water-cooled divertor target", Nuclear Materials and Energy, vol. 5, pp. 7-18, 2015.

[2] V. Barabash, A. Peacock, S. Fabritsiev, G. Kalinin, S. Zinkle, A. Rowcliffe, et al., "Materials challenges for ITER - Current status and future activities", Journal of Nuclear Materials, vol. 367-370, pp. 21-32, 2007.

[3] J. H. You, G. Mazzone, E. Visca, C. Bachmann, E. Autissier, T. Barrett, et al., "Conceptual design studies for the European DEMO divertor: Rationale and first results", Fusion Engineering and Design, vol. 109-111, pp. 1598-1603, 2016.

[4] J.-H. You, "A review on two previous divertor target concepts for DEMO: mutual impact between structural design requirements and materials performance", Nuclear Fusion, vol. 55, p. 113026, 2015.

[5] ITER Structural Design Criteria for In-Vessel Components (SDCIC), ITER Organization, 2004.

[6] M. Appello and P. Fenici, "Solution heat treatment of a Cu-Cr-Zr alloy", Materials Science and Engineering: A, vol. 102, pp. 69-75, 1988.

[7] A. K. Nikolaev, A. I. Novikov, and V. M. Rozenberg, "Chromium Bronzes", Maetallurgiya, 1983.

[8] British Standards Institution (BSI), Copper and copper alloys-Rod for general purposes, 2011,

[9] Copper Development Association Inc., Standard Designation for Wrought Copper Alloys, 2018,

[10] R. Wei, Q. Li, W. J. Wang, J. C. Wang, X. L. Wang, C. Y. Xie, et al., "Microstructure and properties of $\mathrm{W}-\mathrm{Cu} / \mathrm{CuCrZr/316L}$ joint bonded by one-step HIP technique", Fusion Engineering and Design, vol. 128, pp. 47-52, 2018.

[11] J.-Y. Park, J.-S. Lee, B.-K. Choi, B. G. Hong, and Y. H. Jeong, "Effect of cooling rate on mechanical properties of aged ITER-grade CuCrZr", Fusion Engineering and Design, vol. 83, pp. 1503-1507, 2008.

[12] X. W. Zhang, X. Zhou, Q. J. Wang, and B. Liang, "Tensile Behavior of High Temperature $\mathrm{Cu}-\mathrm{Cr}-\mathrm{Zr}$ Alloy", presented at the International Conference on Power Electronics and Energy Engineering, 2015.

[13] B. Zhang, Z.-g. Zhang, and W. Li, "Mechanical properties, electrical conductivity and microstructure of $\mathrm{CuCrZr}$ alloys treated with thermal stretch process", Transactions of Nonferrous Metals Society of China, vol. 25, pp. 2285-2292, 2015.

[14] KME Germany GmbH \& Co. KG, ELBRODUR Alloys for resistance welding, 2015,

[15] M. Li, M. A. Sokolov, and S. J. Zinkle, "Tensile and fracture toughness properties of neutron-irradiated CuCrZr", Journal of Nuclear Materials, vol. 393, pp. 36-46, 2009.

[16] V. Barabash, K. Ioki, M. Merola, G. Sannazzaro, and N. Taylor, Materials for the ITER vacuum 
vessel and in-vessel components- current status, 2010.

[17] B. N. Singh, D. J. Edwards, and S. Tähtinen, Effect of heat treatments on precipitate microstructure and mechanical properties of CuCrZr alloy, Ris $\varnothing$ National Laboratory, 1436(EN), 2004.

[18] B. N. Singh, M. Li, J. F. Stubbins, and B. S. Johansen, Creep-Fatigue Deformation Behaviour of OFHC-Copper and CuCrZr Alloy with Different Heat Treatments and with and without Neutron Irradiation, Risø-Report, Risø-R-1528(EN), 2005.

[19] B. N. Singh, S. Tähtinen, P. Moilanen, P. Jacquet, J. Dekeyser, D. J. Edwards, et al., "Final report on in-reactor creep-fatigue deformation behaviour of a CuCrZr alloy: COFAT1", 2007.

[20] Outokumpu. Available: https://www.outokumpu.com/

[21] E. Gaganidze, F. Gillemot, I. Szenthe, M. Gorley, M. Rieth, and E. Diegele, "Development of EUROFER97 database and material property handbook", Fusion Engineering and Design, vol. 135, pp. 9-14, 2018.

[22] RCC-MRx, Design and Construction Rules for mechanical components of nuclear installations: high temperature, research and fusion reactors, 2018,

[23] M. Li and S. J. Zinkle, Physical and Mechanical Properties of Copper and Copper Alloys: Elasevier, 2012.

[24] P. Marmy and O. Gillia, "Investigations of the effect of creep fatigue interaction in a Cu-Cr-Zr alloy", Procedia Engineering, vol. 2, pp. 407-416, 2010.

[25] L. A. Thi Nguyen, S. Lee, S. J. Noh, S. K. Lee, M. C. Park, W. Shu, et al., "Desorption dynamics of deuterium in CuCrZr alloy", Journal of Nuclear Materials, vol. 496, pp. 117-123, 2017.

[26] S. Tähtinen, M. Pyykkönen, P. Karjalainen-Roikonen, B. N. Singh, and P. Toft, "Effect of neutron irradiation on fracture toughness behaviour of copper alloys", Journal of Nuclear Materials, vol. 258-263, pp. 1010-1014, 1998.

[27] S. A. Fabritsiev, S. J. Zinkle, and B. N. Singh, "Evaluation of copper alloys for fusion reactor divertor and first wall components", Journal of Nuclear Materials, vol. 233-237, pp. 127-137, 1996.

[28] B. N. Singh, D. J. Edwards, and S. Tähtinen, Effect of heat treatments on precipitate microstructure and mechanical properties of CuCrZr alloy, Ris $\varnothing-R-1436(E N), 2004$.

[29] G. Kalinin and R. Matera, "Comparative analysis of copper alloys for the heat sink of plasma facing components in ITER", Journal of Nuclear Materials, vol. 258-263, pp. 345-350, 1998.

[30] G. M. Kalinin, A. S. Artyugin, M. V. Yvseev, V. V. Shushlebin, L. P. Sinelnikov, and Y. S. Strebkov, "The effect of irradiation on tensile properties and fracture toughness of CuCrZr and CuCrNiSi alloys", Journal of Nuclear Materials, vol. 417, pp. 908-911, 2011.

[31] G. Kalinin, V. Barabash, A. Cardella, J. Dietz, K. loki, R. Matera, et al., "Assessment and selection of materials for ITER in-vessel components", journal of Nuclear Materials, vol. 283-287, pp. 10-19, 2000.

[32] B. N. Singh, D. J. Edwards, and P. Toft, "Effects of neutron irradiation on mechanical properties and microstructures of dispersion and precipitation hardened copper alloys", Journal of Nuclear Materials, vol. 238, pp. 244-259, 1996.

[33] S. A. Fabritsiev, A. S. Pokrovsky, D. J. Edwards, and S. J. Zinkle, "The effect of neutron dose, irradiation and testing temperature on mechanical properties of copper alloys", Journal of Nuclear Materials, vol. 258-263, pp. 1015-1021, 1998.

[34] M. Li and J. F. Stubbins, "Evaluation of Irradiation Effect on Fatigue Performance of Copper 
Alloys for High Heat Flux Applications", Fusion Science and Technology, vol. 44, pp. 186-190, 2003.

[35] G. Li, B. G.Thomas, and J. F. Stubbins, "Modeling Creep and Fatigue of Copper Alloys", Metallurgical and Materials Transactions A, vol. 31A, pp. 2491-2502, 2000.

[36] H. Nishi and M. Enoeda, "Effect of HIP temperature on microstructure and low cycle fatigue strength of CuCrZr alloy", Journal of Nuclear Materials, vol. 417, pp. 920-923, 2011.

[37] P. Marmy, "In-beam mechanical testing of CuCrZr", Journal of Nuclear Materials, vol. 329-333, pp. 188-192, 2004.

[38] K. D. Leedy, J. F. Stubbins, B. N. Singh, and F. A. Garner, "Fatigue behavior of copper and selected copper alloys for high heat flux applications", Journal of Nuclear Materials, vol. 233-237, pp. 547-552, 1996.

[39] P. Marmy, "Creep-Fatigue of Cu-Cr-Zr: A Review of the existing Fatigue, Creep and Creep-Fatigue Data Base and a Life Prediction Analysis using a Time based Damage Evaluation", 2005.

[40] G. Pintsuk, J. Blumm, W. Hohenauer, R. C. Hula, T. Koppitz, S. Lindig, et al., "Interlaboratory Test on Thermophysical Properties of the ITER Grade Heat Sink Material Copper-ChromiumZirconium", International Journal of Thermophysics, vol. 31, pp. 2147-2158, 2010.

[41] ZOLLERN. Available: https://www.zollern.com

[42] ITER Document No. G74 MA16, ITER Material Properties Handbook, File Code: ITER-AK02-3112.

[43] ITER Document No. S74 MA2, ITER Material Properties Handbook, File code : ITER-AK02-3112.

[44] G. Pintsuk, E. Diegele, S. L. Dudarev, M. Gorley, J. Henry, J. Reiser, et al., "European materials development: Results and perspective", Fusion Engineering and Design, 2019, https://doi.org/10.1016/j.fusengdes.2019.02.063. 